\title{
PENGEMBANGAN DOKUMENTASI KEPERAWATAN BERBASIS ELEKTRONIK DI RS X KOTA DEPOK DENGAN MENGGUNAKAN TEORI PERUBAHAN LEWINS
}

\author{
Dyah Fitri Wulandari ${ }^{1}$,Hanny Handiyani ${ }^{2}$ \\ Universitas Indonesia FIK Magister Kekhususan Kepemimpinan dan \\ Manajemen Keperawatan Fakultas Ilmu Keperawatan
}

\begin{abstract}
Background: Nursing documentation in Indonesia is still much in the form of paper based documentation. Many weaknesses in this documentation model, so it needs to be innovated by using electronic-based nursing documentation. Problems that occur in $R S$ $X$ in the development of electronic-based nursing documentation are the factors of leadership, factors of means and factors of follow-up development of electronic nursing documentation. Method: In solving this problem, it is recommended to use Lewin's theory of change which consists of three phases: unfreezing, moving, and refreezing. Result: Stages of unfreezing: conducting evidence-based and literature review studies on the importance of electronic documentation, and brainstorming with the nurse actors change Phase Moving implementing the stages of implementation of electronic documentation development using the principles of 5 management functions namely planning, organizing, staffing, leading and controlling. Refreezing stages: provide supervisors, make Decree of Director and Standard of Operational Procedure about implementation of electronic-based nursing documentationin X Hospital Depok. Conclusion: In solving this problem, Lewin's theory of change consists of three pairs, namely unfreezing, moving, and refreezing.
\end{abstract}

Keywords: Lewin's Theory of Change, Electronic-Based Nursing Documentation, Recommendations

\section{PENDAHULUAN}

Dokumentasi keperawatan adalah setiap catatan baik tertulis maupun elektronik yang menggambarkan layanan keperawatan yang diberikan kepada klien dan dapat digunakan sebagai bukti bagi tenaga yang berwenang. Dokumentasi keperawatan yang berlaku di rumah sakit saat ini umumnya dilakukan secara tertulis (paper based documentation). Metode ini mempunyai kelemahana yaitu memerlukan waktu yang cukup lama untuk mengisi form yang tersedia, membutuhkam biaya percetakan form yang cukup mahal, sering hilang atau terselip, memerlukan tempat penyimpanan yang luas dan menyulitkan pencarian kembali saat diperlukan. (Hadi, 2011). Disamping itu masih banyak perawat yang tidak tahu data apa yang harus dimasukkan dan bagaimana dokumentasi keperawatan yang benar, untuk itu perlu adanya inovasi pencatatan dengan menggunakan pencatatan berbasis elektronik. Pencatatan berbasis elektronik telah lebih dahulu dilakukan oleh negara negara maju, namun di Indonesia baru dilakukan pada tahun 2000-an. Dokumentasi keperawatan berbasis elektronik ini memberikan keuntungan 
bagi perawat dalam hal waktu pendokumentasian yang lebih singkat, keterbacaan data dan kemudahan akses bila dibandingkan dokumentasi dalam format kertas. Pengembangan dokumentasi keperawatan berbasis elektronik tetap harus memperhatikan prinsip kerahasiaan data klien, komprehensif, akurat, tepat waktu, dan jelas mengidentifikasi pemberi perawatan sehingga perlu adanya kebijakan dan pedoman yang jelas bagi tenaga perawat dalam menjalankan sistem ini.

Di sebuah rumah sakit $X$ di Kota Depok, telah dikembangkan aplikasi dokumentasi berbasis elektronik yaitu menggunakan Sistem Informasi Keperawatan (SIMPRO) pada tahun 2016. Namun saat ini masih dipakai dokumentasi berbasis kertas. Permasalahan yang ada adalah tidak tersedianya sarana yang memadai, yaitu belum adanya server yang cukup menampung aplikasi SIMPRO ini, adanya survey akreditasi yang membuat jajaran direksi keberatan apabila model dokumentasi keperawatan dirubah dari berbasis kertas menjadi berbasis elektronik. Selain itu belum dilakukannya tindak lanjut dari bidang keperawatan terhadap pelaksanaan uji coba aplikasi SIMPRO ini. Berbagai masalah yang ada perlu dicari penyelesaiannya agar metode SIMPRO yang sudah ada di RS X bisa segera dipakai sebagai bentuk dokumentasi keperawatan.

\section{METODE PENELITIAN}

Metode yang digunakan dalam penulisan manuskrip adalah studi literatur dari sumber buku dan jurnal, serta deskripsi hasil kunjungan. Metode yang digunakan dalam kunjungan ke RS X adalah wawancara dan observasi.
Wawancara dilakukan kepada jajaran direksi, kepala ruangan, perawat pelaksana, dan staf IT RS X. Observasi dilakukan untuk melihat dokumentasi keperawatan yang dilakukan perawat di ruang rawat inap.

\section{HASIL PENELITIAN}

Berdasarkan hasil wawancara dengan jajaran direksi terdiri dari Direktur dan Kepala Bidang Pelayanan yang saat ini juga sebagai plt. Kepala Bidang Keperawatan didapatkan hasil bahwa jajaran direksi belum yakin bahwa dokumetasi elektronik bisa diterima oleh surveyor akreditasi, selain itu mereka menganggap belum diperlukan dokumentasi keperawatan elektronik saat ini. Apabila hanya perawat saja yang berubah memakai dokumentasi elektronik maka akan terjadi dualisme bentuk dokumentasi di RS X. Wawancara terhadap Kepala Ruangan dan staf dan observasi dokumentasi keperawatan didapatkan data bahwa banyak keluhan tentang perawat yang lebih sering menulis dibandingkan waktu memberikan pelayanan ke pasien. Namun dari hasil observasi kelengkapan dokumentasi keperawatan didapatkan masih banyak dokumentasi keperawatan yang tidak lengkap, isi dokumentasi keperawatan tidak sesuai dengan kondisi pasien dan perawat mengeluh banyak sekali format dokumentasi yang harus diisi, satu dengan yang lain mempunyai persepsi yang berbeda tentang cara penulisan dokumentasi.

Hasil wawancara terhadap staf perawat yang telah menikuti pelatihan SIMPRO pada tahun 2016 menghasilkan data sebagai berikut : perawat merasakan kemudahan saat mengisi dokumentasi keperawatan dengan menggunakan 
SIMPRO, dan perawat menginginkan SIMPRO dilaksanakan di ruang perawatan.

Hasil wawancara terhadap staf IT RS X, didapatkan data bahwa server yang ada saat ini bisa dipakai hanya untuk ruang rawat inap saja, dan dipastikan harus bagus koneksi internetnya, supaya dokumentasi berbasis elektronik ini berjalan lancar.

Dalam memecahkan rangkaian masalah diatas digunakanlah metode perubahan menurut Lewin. Model perubahan Kurt Lewin menawarkan pendekatan terstruktur yang dapat membantu perawat mengidentifikasi kebutuhan akan perubahan, menavigasi melalui proses perubahan, dan mencapai tujuan atau hasil yang diinginkan. (Payne, 2013) Pendekatan Lewin untuk manajemen perubahan sangat bermanfaat bagi keperawatan. Pendekatan ini juga dapat membantu perawat dalam menganalisis proses perubahan dan dalam mengidentifikasi kekuatan yang mendukung atau menolak perubahan $(\mathrm{G}$ Bozak, 2003). Lewin mengidentifikasi kekuatan ini sebagai kekuatan pendorong dan kekuatan penahanan.(Kaminski, 2011). Menurut Kaminski (2011), kekuatan pendorong memulai perubahan dan membantu organisasi mencapai tujuan yang mereka inginkan. Kekuatan penahan, di sisi lain, adalah kekuatan statis yang melawan kekuatan pendorong dan mencegah terjadinya perubahan.Bila kekuatan pendorong dan kekuatan penahan setara, keadaan ekuilibrium tercapai. Agar perubahan terjadi, keadaan ekuilibrium ini harus terganggu (Bozak, 2003; Kaminski,2011). Hal ini terjadi ketika kekuatan pendorong lebih kuat daripada gaya menahan, atau sebaliknya, ketika kekuatanpenahan lebih lemah daripada gaya penggerak (Bozak, 2003; Kaminski, 2011)

\section{PEMBAHASAN}

Teori perubahan Lewin terdiri dari tiga tahap: unfreezing, moving, and refreezing(Judge, Timothy A_Robbins, 2017). Unfreezing adalah tahap awal proses manajemen perubahan. Pada tahap ini, individu mengenali kebutuhan akan perubahan dan bersiap menghadapi perubahan yang terjadi. Langkah ini sering menimbulkan perubahan perilaku di antara individu. Bozak (2003) menyatakan bahwa perasaan tidak nyaman, ketakutan, dan kesusahan mungkin dialami selama periode ini. Untuk maju ke tahap berikutnya, perawat harus mengenali dan menangani secara memadai perilaku ini, serta kekuatan resistif lainnya. Selain itu, perawat perlu menganalisis kekuatan pendorong untuk menentukan apakah mereka lebih hebat daripada kekuatan penahan. Mendidik individu mengenai motif perubahan dapat meningkatkan kekuatan kekuatan pendorong dan memfasilitasi transisi dari tahap pertama ke tahap kedua model Lewin (Bozak, 2003; Kaminski, 2011)

Langkah kedua dari proses perubahan dikenal sebagai bergerak (moving) (Bozak, 2003; Kaminski, 2011). Pada titik ini, strategi manajemen perubahan harus diarahkan untuk memperkuat kekuatan pendorong atau melemahnya kekuatan penahanan yang dihadapi oleh organisasi. Selain itu, perlu dilakukan inisiatif untuk mendorong individu bahwa perubahan diinginkan akan membawa perubahan organisasi yang positif. Individu yang memahami manfaat ini lebih cenderung mendukung perubahan yang diajukan dan secara aktif 
terlibat dalam aktivitas yang mendorong perubahan ke depan dan justru menyebabkan perubahan terjadi (Judge, Timothy A_Robbins, 2017). Langkah ketiga, dan terakhir dari proses Lewin adalah refreezing. Pada langkah ini, ekuilibrium telah berhasil dicapai. Akibatnya, perubahan dimasukkan ke dalam prosedur dan aktivitas rutin di dalam organisasi. Untuk mencegah individu mengalami kemunduran ke keadaan sebelumnya, sangat penting untuk terus mempertahankan dan mengevaluasi kembali perubahan yang telah ada Hal ini dapat dicapai melalui penggunaan mekanisme pendukung seperti kebijakan, penghargaan, pendidikan dan pelatihan, serta kompetensi antar ruangan (Kaminski, 2011).

Dari pembahasan teori perubahan diatas maka dilakukan pemecahan masalah menggunakan metode perubahan Kurt Lewins. Masalah yang teridentifkasi adalah adanya masalah pada faktor pimpinan, faktor sarana dan faktor tindak lanjut pengembangan SIMPRO. Mengikuti model Lewin, langkah pertama dari proses perubahan melibatkan "unfreezing" perubahan. Untuk mencapai langkah ini, perawat perancang perubahan perlu mengidentifikasi dan memprioritaskan kekuatan pendorong dan kekuatan penahan. Dari kondisi di RS X dapat dipetakan sebagai berikut: untuk kekuatan penahan dari kalangan direksi, untuk kekuatan pendorong dari kalangan kepala ruangan dan staf keperawatan sebagai kekuatan pendorong.

Setelah semua kekuatan ini teridentifikasi, perawat harus melanjutkan untuk mengembangkan sebuah rencana untuk memperkuat kekuatan pendorong dan melemahkan atau menghilangkan kekuatan penahan. .

Bozak (2003) mengidentifikasi kekuatan pendorong yang berkaitan dengan penerapan dokumentasi elektronik meliputi: keinginan untuk memperbaiki metode dokumentasi, kepercayaan bahwa dokumentasi elektronik akan memfasilitasi akses terhadap informasi klinis yang akurat dan komprehensif, pengalaman sebelumnya dengan komputer, dan sikap positif terhadap komputerisasi. Kekuatan pendorong potensial lainnya meliputi: pelatihan yang memadai, manajemen yang mendukung, keinginan untuk memperluas pengetahuan pribadi, sumber keuangan yang memadai, dan budaya organisasi yang positif. Oleh karena itu kekuatan pendorong harus di kuatkan, dengan melakukan brainstorming untuk meminta masukan terhadap pelaksanaan SIMPRO ini, dan melakukan pelatihan ulang untuk pemakaian SIMPRO.

Penelitian tentang self efficasi perawat dalam menggunakan SIMPRO, perlu di jadikan pertimbangan dalam mengembangan aplikasi SIMPRO di RS X.(Sartika, Dewi; Hariyati, Tutik Sri; Noviestasari, 2014). Self efficacy perawat penting dalam penggunaan SIMPRO karena dapat menentukan keberhasilan penggunaan, meningkatkan kualitas dokumentasi keperawatan dan kualitas pelayanan keperawatan. Penelitian fenomenologi ini mengeksplorasi self efficacy perawat dalam penggunaan sistem informasi keperawatan (SIMPRO) di RSIA Bunda Jakarta. Hal baru yang ditemukan pada penelitian ini yaitu munculnya kepercayaan diri menggunakan SIMPRO dengan faktor faktor sebagai berikut adanya keyakinan diri untuk bisa menggunakan SIMPRO, 
tertarik terhadap teknologi SIMPRO, paham terhadap SIMPRO, dan sering menggunakan SIMPRO. Faktor kendala dalam menggunakan SIMPRO yaitu terdiri atas kendala terkait perangkat SIMPRO dan kendala dari rekan kerja. Kendala terkait perangkat SIMPRO terdiri atas loading lama, loading error, dan tidak ada sinyal. Sedangkan kendala dari rekan kerja, yaitu rekan kerja malas menggunakan SIMPRO perlu diantisipasi Direkomendasikan kepada perawat untuk meningkatkan self efficacy melalui mempelajari SIMPRO, dan mengikuti pelatihan tentang SIMPRO serta melanjutkan pendidikan agar dapat mengoptimalkan peran dan fungsi-fungsi manajemen untuk meningkatkan self efficacy perawat dalam menggunakan SIMPRO.

Bozak

juga

mengidentifikasi kemungkinan kekuatan penahanan seperti pelatihan yang tidak memadai, manajemen yang tidak mendukung, keengganan untuk mempelajari sesuatu yang baru, sumber keuangan yang tidak mencukupi, dan budaya organisasi yang negatif. Kekuatan penahanan lainnya meliputi: keinginan untuk terus menggunakan dokumentasi berbasis kertas, kurangnya pengalaman komputer, dan sikap negatif terhadap komputer. Sangat penting bagi perawat informatika untuk menjaga komunikasi terbuka dengan staf perawat dan melibatkan mereka di semua tahap proses perencanaan (Bozak, 2003). Untuk kekuatan penahan, perlu dilakukan komunikasi yang yang lebih intensif dengan membuat telaah tentang perlunya SIMPRO ini. Telah berbasis evidence based, dengan menggunakan jurnal jurnal terkait perlu dilakukan.
Penelitian yang dilakukan pada pelaksanaan SIMPRO di RS Dompet Dhuafa menunjukan hasil sebagai berikut : terdapat perbedaan kelengkapan dan waktu pendokumentasian asuhan keperawatan yang bermakna antara sebelum 1,63 (40,75\%) dan 472,5 detik (7,9 menit): sesudah penerapan SIMPRO $3,13(78,25 \%)$ dan 189,88 detik (3,2 menit). Hasil uji statistik menunjukkan bahwa jenis kelamin ( $=0,408 \quad \&$ $\mathrm{p}=0,285)$, tingkat pendidikan $(\mathrm{p}=0,315 \&$ $\mathrm{p}=0,906)$. Pengalaman $(\mathrm{p}=0,193 \& \mathrm{p}=$ 0,181), kemampuan menggunakan komputer $(\mathrm{p}=0,314 \& \mathrm{p}=0,500)$ tidak berhubungan dengan kelengkapan dan waktu dokumentasi asuhan keperawatan setelah penerapan SIMPRO. Demikian implikasi hasil penelitian mengenai pengaruh penerapan SIMPRO terhadap pelayanan keperawatan di RS Dompet Dhuafa (Dwisatyadini, 2014).

Dalam penelitian lain tentang optimalisasi kinerja SIMPRO menghasil data sebagai berikut: hasil riset menyampaikan ada perbedaan kinerja sebelum dan sesudah menggunakan SIMPRO yang diidentifikasikan dari perbedaan kualitas, kelengkapan, kesinambungan, bukti aspek legal dan fungsi membantu membuat keputusan $(p=0.001)$. Ada perbedaan efisiensi waktu: baik di Rumah Sakit Ibu dan Anak Bunda Jakarta dan RS. Fatmawati $(p=$ 0.01). Setelah menggunakan SIMPRO waktu yang diperlukan untuk melaksanakan dokumentasi di RS Fatmawati adalah 40.29 menit atau $25.27 \%$ dari total waktu dalam satu shift, sedangkan di RS Ibu dan Anak Bunda Jakarta membutuhkan waktu 24.62 menit atau $9.60 \%$ dari total waktu dalam satu shift. SIMPRO juga mempengaruhi efisiensi biaya, dimana dengan SIMPRO 
dokumentasi tidak setiap waktu harus dicetak. SIMPRO menjamin continuity of care dari asuhan keperawatan, sebagai bukti aspek legal, membantu mengambil keputusan dan meningkatkan keselamatan pasien. SIMPRO mengefisiensikan waktu dokumentasi sehingga waktu perawatan langsung ke pasien lebih optimal. SIMPRO juga meningkatkan edukasi kesehatan kepada pasien dan keluarga. Pada riset ini SIMPRO juga dapat meningkatkan peran manajer keperawatan dalam melaksanakan fungsi manajemen terutama pada peran pemberiaan motivasi, pengarahan, evaluasi dan monitoring terhadap pelaksanaan asuhan keperawatan. Dukungan aspek perawat, aspek manajemen dan teknik dapat mengoptimalkan kinerja SIMPRO sehingga dapat meningkatkan kualitas pelayanan keperawatan. Berdasarkan manfaat dari SIMPRO, maka sistem ini dapat direkomendasikan untuk digunakan di setiap Rumah Sakit serta dapat mendukung peningkatan kualitas mutu pelayanan keperawatan dan kesehatan (Hariyati, 2012).

Penelitian lain di sebuah RS Daerah di Jawa Tengah dengan kondisi yang hampir sama dengan RS $\mathrm{X}$ menunjukkan bahwa bahwa dengan dokumentasi berbasis elektronik, perawat memiliki kinerja pendokumentasian baik sebanyak 52,6\%. (Pramithasari. \& Diah, 2016). Hasil - hasil penelitian di atas bisa dimasukan dalam telaah pentingnya penggunaan SIMPRO.

Tahapan pertama dari model Lewin bisa dilalui apabila semua skateholder yang ikut berperan dalam pelaksanaan SIMPRO merasakan perlu untuk dilakukan perubahan, dan memberikan dukungan penuh terhadap SIMPRO ini. Terutama kekuatan penahan yang berubah menjadi kekuatan pendorong dalam sebuah proyek perubahan.

Langkah kedua model Lewin melibatkan pembuat rencana perubahan yang diusulkan pada langkah pertama, dan benar-benar menerapkan perubahan tersebut (Bozak, 2003; Kaminski, 2011). Seperti pada langkah sebelumnya, perawat perancang perubahan harus terus berkomunikasi dengan staf perawat dan mengetahui saran dan pendapat mereka. Informer perawat juga membantu staf mengenali manfaat dokumentasi elektronik. Menurut Bozak (2003), karyawan lebih cenderung mendukung perubahan jika mereka memahami manfaat dokumentasi elektronik dan terlibat aktif selama proses perencanaan dan pelaksanaan. Perawat juga harus terus memantau perubahan perilaku staf dan perilaku selama tahap ini (Bozak, 2003). Tidak diragukan lagi, penerapan dokumentasi elektronik akan mengganggu perubahan normal dalam alur kerja, yang dapat menimbulkan perasaan negatif atau perilaku di antara staf. Jika ini terjadi, perawat perancang perubahan harus kembali ke strategi yang digunakan selama tahap unfreezing (Bozak, 2003; Kaminski, 2011).

Pada tahap ini perawat perancang perubahan diharapkan memakai prinsip prinsip manajemen keperawatan dalam melakukan perubahan. Swansburg (1999) menyatakan bahwa fungsi manajemen terdiri atas lima fungsi yaitu perencanaan (planning), pengorganisasian (organizing), pengaturan staf (staffing), kepemimpinan (leading), dan pengendalian (controlling). Perencanaan (Planning) merupakan fungsi dasar dari manajemen. Perencanaan dalam manajemen keperawatan adalah proses 
dimana semua manajer perawat menggunakan data yang valid dan dapat dipercaya untuk mengembangkan objektif dan menentukan sumber-sumber yang dibutuhkan dan cetak biru yang digunakan dalam mencapai tujuan. Tujuan utama dari perencanaan adalah membuat kemungkinan yang paling baik dalam penggunaan personel, bahan, dan alat (Swansburg, Russell C; Swansburg, 1999). Fungsi perencanaan mencakup proses merumuskan sasaran, membangun strategi untuk mencapai sasaran yang telah disepakati, dan mengembangkan perencanaan tersebut untuk memadukan dan mengkoordinasikan sejumlah kegiatan. Pada perenecanaaan ini, dilakukan rencana melakukan sosialisasi untuk mendapatkan masukan terkait pelaksanaan SIMPRO, pembentukan tim inti SIMPRO, rencana pelatihan ulang SIMPRO, rencana pertemuan pertemuan lanjutan, dan rencana ruangan yang dijadikan pilot project, dan rencana penambahan server untuk tahun depan. Waktu yang diperlukan, tujuan yang akan dicapai dan strategi yang akan dipakai dibahas juga dalam perencanaan ini.

Fungsi berikutnya dalam manajemen keperawatan adalah fungsi pengorganisasian yaitu fungsi manajemen yang berhubungan dengan mengalokasi dan mengatur sumber daya untuk menyelesaikan tujuan yang dicapai. Peran manajer dalam fungsi pengorganisasian adalah menentukan tugas yang akan dikerjakan, individu yang akan mengerjakan, pengelompokkan tugas, struktur pertanggungjawaban, dan proses pengambilan keputusan. Manajer bertanggung jawab juga dalam merancang pekerjaan staf yang digunakan untuk mencapai tujuan yang diharapkan. Maka pada tahapan ini di buatlah deskripsi kerja, penanggung jawab, cara pelaporan, cara supervisi bagi individu yang terlibat dalam pelaksanaan SIMPRO.

Setelah tahapan pengorganisasian telah berjalan baik, maka fungsi berikutnya adalah staffing (pengaturan staf). Pengaturan staf keperawatan merupakan proses yang teratur, sistematis, rasional diterapkan untuk menentukan jumlah dan jenis personel keperawatan yang dibutuhkan untuk melakukan proyek perubahan. Pada tahapan ini dilakukan pelaksanaan pelatihan ulang SIMPRO, dilakukan pembagian staf keperawatan yang ikut pelatihan awal SIMPRO ini, dipilih yang bisa menjadi agen perubahan di ruang rawat. Pengaturan staf untuk melakukan supervisi terhadap pelaksaan SIMPRO perlu dilakukan juga, selain itu koordinasi dengan staf IT RS X juga harus di sepakati di tahap ini.

Fungsi kepemimpian (leading) adalah fungsi selanjutnya. Kepemimpinan merupakan proses mempengaruhi kelompok untuk menentukan dan mencapai tujuan. Kepemimpinan difokuskan kepada gaya kepemimpinan situasi kemungkinan dan faktor-faktor seperti manusia, pekerjaan, situasi, organisasi, dan faktor-faktor lingkungan. Manajer perawat dalam fungsi ini berperan untuk merangsang motivasi dengan mempraktikkan fungsi kepemimpinan karena perilaku motivasi merupakan promosi, autonomi, membuat keputusan, dan manajemen partisipasi (Swansburg, 1999). Pada tahap ini perawat perancang berubahan harus meningkatkan motivasi para peserta perubahan, dengan berbagai cara antara lain, mendampingi saat proses perubahan dilakukan, melakukan promosi kegiatan 
perubahan ke seluruh komponen rumah sakit (termasuk kepada pimpinan rumah sakit), membantu menyelesaikan masalah masalah yang timbul dan apabila memungkinkan memberikan penghargaan terhadap para peserta perubahan yang aktif melakukan kegiatan ini.

Fungsi akhir dari manajemen adalah pengendalian atau pengevaluasian (controlling) Pengendalian atau pengevaluasian adalah suatu fungsi yang terus menerus dilakukan oleh manajer keperawatan yang terjadi selama perencanaan, pengorganisasian, dan pengerahan aktivitas. Melalui prsoses ini standar dibuat dan kemudian digunakan, diikuti umpan balikyang menimbulkan perbaikan (Swansburg, 1999). Fungsi pengendalian adalah fungsi yang digunakan untuk memantau dan mengatur perencanaan, proses, dan sumber daya manusia yang efektif dan efisien untuk mencapai tujuan-tujuan yang telah direncanakan sebelumnya. Pada tahapan ini perawat perancang perubahan mengadakan rapat rapat evaluasi sesuai yang telah di rencanakan. Rapat evaluasi dilakukan untuk lebih menyempurnakan pelaksanaan SIMPRO di ruang rawat, mengevaluasi apakah tujuan yang di rencanakan sudah tercapai, dan tindak lanjut yang akan dilakukan setelah tujuan tercapai. Sehingga pelaksaan SIMPRO dapat berjalan lancar dan bisa berlanjut menjadi model dokumentasi keperawatan di RS X. Begitu peserta perubahan telah menerima dan berhasil beralih dari kertas ke dokumentasi elektronik, organisasi dapat melanjutkan ke tahap akhir model Lewin.

Pada tahap ini, RS $\mathrm{X}$ akan menggunakan sistem komputerisasi untuk secara elektronik dalam melakukan dokumentasi keperawatan. Tahap refreezing adalah waktu untuk menstabilkan dan mengevaluasi kembali perubahan tersebut ke dokumentasi elektronik (Bozak, 2003). Perawat perancang perubahan dapat mempertahankan perubahan ini dengan memberi staf pelatihan lanjutan dan dukungan yang terus menerus. Untuk proyek SIMPRO ini, penting untuk memiliki teknologi informasi yang tersedia sepanjang waktu untuk mengatasi masalah dan masalah umum terkait sistem komputerisasi. Supervisor juga harus tersedia untuk mendukung staf dan memberikan pelatihan komprehensif untuk karyawan baru. Selain itu, kebijakan berbentuk Surat Keputusan Direkturdan Standar Prosedur Operasional (SPO) harus tersedia untuk membantu staf dalam proses dokumentasi (Kaminski, 2011). Evaluasi berkelanjutan juga penting untuk menentukan apakah sistem dokumentasi ini sudah memenuhi standar profesional, akreditasi dan organisasi, atau jika ada perubahan tambahan yang perlu dilakukan untuk memperbaiki metode dokumentasi elektronik ini lebih lanjut.

\section{KESIMPULAN DAN SARAN}

Kesimpulan:

Dokumentasi keperawatan yang berlaku di rumah sakit saat ini umumnya dilakukan secara tertulis (paper based documentation). Metode ini mempunyai kelemahan yaitu memerlukan waktu yang cukup lama untuk mengisi form yang tersedia, membutuhkam biaya percetakan form yang cukup mahal, sering hilang atau terselip, memerlukan tempat penyimpanan yang luas dan menyulitkan pencarian kembali saat diperlukan. Diperlukan inovasi dokumentasi keperawatan dengan menggunakan 
dokumentasi berbasis elektronik. Dokumentasi keperawatan berbasis elektronik ini memberikan keuntungan bagi perawat dalam hal waktu pendokumentasian yang lebih singkat, keterbacaan data dan kemudahan akses bila dibandingkan dokumentasi dalam format kertas.

Masalah yang terjadi di RS X dalam pengembangan dokumentasi keperawatan berbasis elektronik adalah faktor pimpinan, faktor sarana dan faktor tindak lanjut pengembangan SIMPRO. Dalam menyelesaikan masalah ini, digunakan teori perubahan Lewin yang terdiri dari tiga tahap yaitu unfreezing, moving, and refreezing.

Saran:

Penyelesaian masalah dengan menggunakan teori perubahan Lewin akan digambarkan sebagai berikut: Tahapan unfreezing :melakukan kajian evidence based dan kajian literatur terhadap pentingnya dokumentasi elektronik, dan melakukan brainstorming dengan perawat pelaku perubahan Tahapan Moving melaksanakan tahapan pelaksanaan pengembangan dokumentasi elektronik dengan menggunakan prinsip 5 fungsi manajemen yaitu planning (rencana sosialisasi SIMPRO, pembentukan tim inti SIMPRO, rencana pelatihan ulang SIMPRO, rencana pertemuan pertemuan lanjutan, rencana ruangan yang dijadikan pilot project, rencana penambahan server untuk tahun depan, rencana waktu yang diperlukan, tujuan yang akan dicapai dan strategi yang akan dipakai), organizing(pembuatan deskripsi kerja, penanggung jawab, cara pelaporan, cara supervisi bagi individu yang terlibat dalam pelaksanaan SIMPRO), staffing (pelatihan ulang SIMPRO, pembagian staf keperawatan yang ikut pelatihan awal SIMPRO untuk menjadi agen perubahan di ruang rawat, pengaturan staf untuk melakukan supervisi, koordinasi dengan staf IT RS X), leading (mendampingi saat proses perubahan dilakukan, melakukan promosi kegiatan perubahan ke seluruh komponen rumah sakit termasuk kepada pimpinan rumah sakit, membantu menyelesaikan masalah masalah yang timbul dan memberikan penghargaan terhadap para peserta perubahan yang aktif melakukan kegiatan ini), controlling(rapat evaluasi untuk lebih menyempurnakan pelaksanaan SIMPRO di ruang rawat, mengevaluasi apakah pencapain tujuan, dan rencana tindak lanjut).

Tahapan refreezing: Menyediakan supervisor, membuat SK dan SPO tentang SIMPRO. Demikian rekomendasi agar permasalahan pengembangan dokumentasi keperawatan berbasis elektronik di RS X dapat diselelesaikan.

\section{DAFTAR PUSTAKA}

Dwisatyadini, M. (2014). Pengaruh Penerapan Simpro Terhadap Kelengkapan dan Efisiensi Waktu Dokumentasi Keperawatan di Instalasi Rawat Jalan RS RST Dompet Dhuafa Parung.(Unpublished doctoral master thesis). Universitas Indonesia, Jakarta

G Bozak, M. (2003). Using Lewin's Force Field Analysis in Implementing a Nursing Information System. Computers, informatics, nursing: CIN (Vol. 21). https://doi.org/10/1097/00024665200303000-00008

Hadi, S. (2011). Analisis Kebutuhan 
Rencana

Dokumentasi

Keperawatan

Rumah Sakit Umum Dr. Kanujoso

Djatiwibowo

Balikpapan.

(Unpublished doctoral master thesis). Universitas Gajah Mada, Yogyakarta.

Hariyati, R. T. S. (2012). Optimalisasi Kinerja Sistem Informasi Manajemen Keperawatan Berbasis Model Simpro. (Unpublished doctoral dissertation thesis). Universita Indonesia, Jakarta.

Judge, Timothy A_Robbins, S. P. (2017). Organizational Behavior. $17^{\text {th }}$ edition. Boston: Pearson Education Limited.

Kaminski, J. (2011). Theory applied to informatics - Lewin's Change Theory. Canadian Journal of Nursing Informatics, 6(c), 4-7. https://doi.org/http://cjni.net/journ al $/ \mathrm{p}=967$

Payne, S. (2013). The Implementation of electronic clinical documentation using Lewin's change management theory. Canadian Journal of Nursing Informatics, 1-8. Retrieved from http://search.proquest.com/openvi ew/bf426131labdfabfec6460259d $36265 \mathrm{~b} 7 / 1$ ?pq-

origsite $=$ gscholar $\&$ cbl $=2026675 \%$ 5Cnpapers3://publication/uuid/6A FC8D39-B165-46C9-B94E05C9631D4BB0

Pramithasari., \& Diah, I. (2016). Gambaran kinerja perawat dalam mendokumentasikan asuhan keperawatan berbasis komputer. Jurnal Keperawatan Muhammadiyah, 1(1). Retrieved from journal.um-surabaya.ac.id Sartika, Dewi; Hariyati , Tutik Sri; Noviestasari, E. (2014). Self Efficacy Perawat Dalam Penggunaan Sistem Informasi Keperawatan Di Rsia Bunda Jakarta: Studi Fenomenologi. Jurnal Keperawatan Indonesia, Volume 17.

Swansburg, Russell C; Swansburg, R. J. (1999). Introduction to Management and Leadership for Nurse Manager (2 nd edition). Boston: Jones and Barlett Publishers. 